\title{
SEBARAN SPASIAL TINGKAT KARSTIFIKASI AREA PADA BEBERAPA MATAAIR DAN SUNGAI BAWAH TANAH KARST MENGGUNAKAN RUMUS RESESI HIDROGRAPH MALIK VOJTKOVA (2012)
}

Tjahyo Nugroho Adji, M Asyroful Mujib 


\section{Latar Belakang}

Karakteristik Imbuhan Airtanah

(Recharge)

Tingkat Perkembangan Akuifer Karst

(Derajat Karstifikasi)

\section{Kapasitas Simpanan Akuifer \\ (Storage)}

Sifat akuifer dalam melepaskan air (Flow)

muda
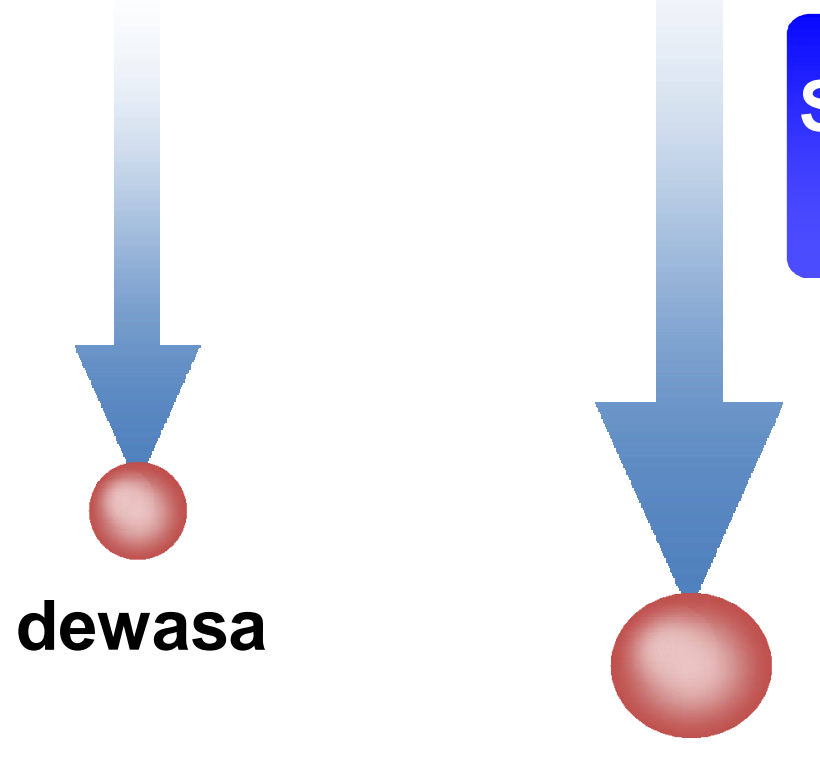

tua 


\section{Tingkat perkembangan karst dari sisi tipe aliran yang dominan}

(a)

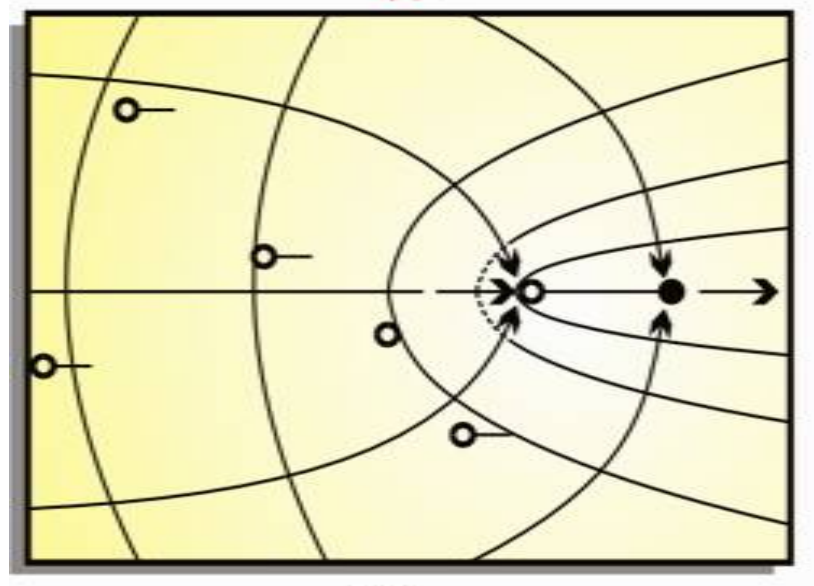

Diffuse (b)

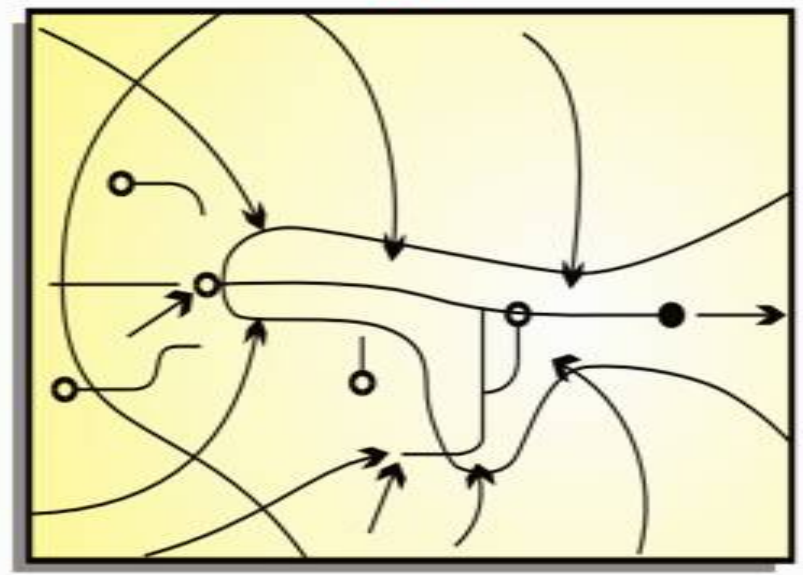

Mixed

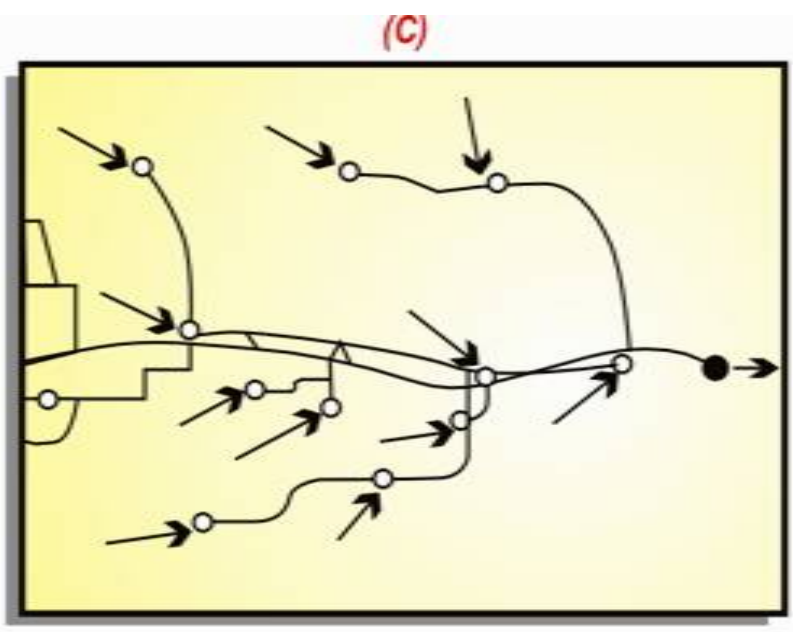

Counduit
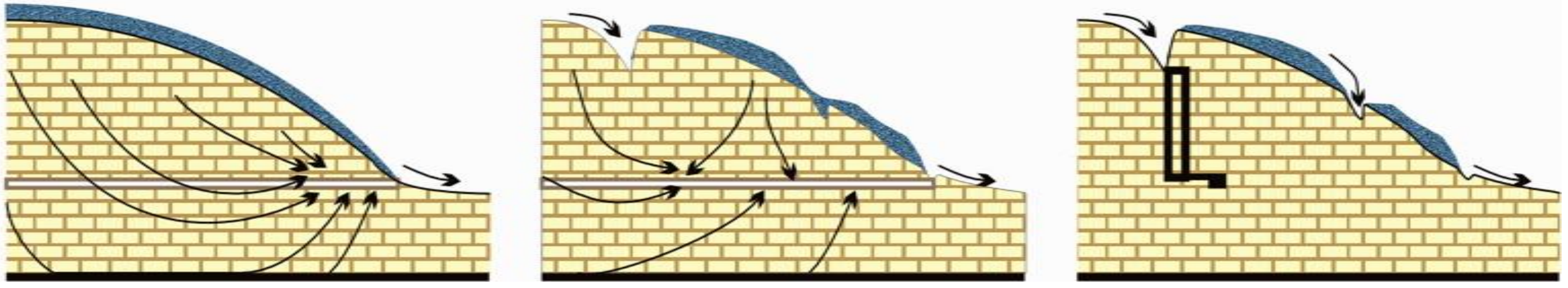


\section{Pendekatan Kualitatif vs Kuantitatif}

\section{Pendekatan Deduktif vs Induktif}

Forward model vs invers model 


\section{Tujuan Penelitian}

Mengetahui perbedaan tingkat perkembangan akuifer karst pada beberapa mataair dan sungai bawahtanah karst

\section{Spasial}

- Kawasan Karst Gunung Sewu, DIY

- Kawasan Karst Rengel, Kab. Tuban, Jatim 


\section{Daerah Penelitian}

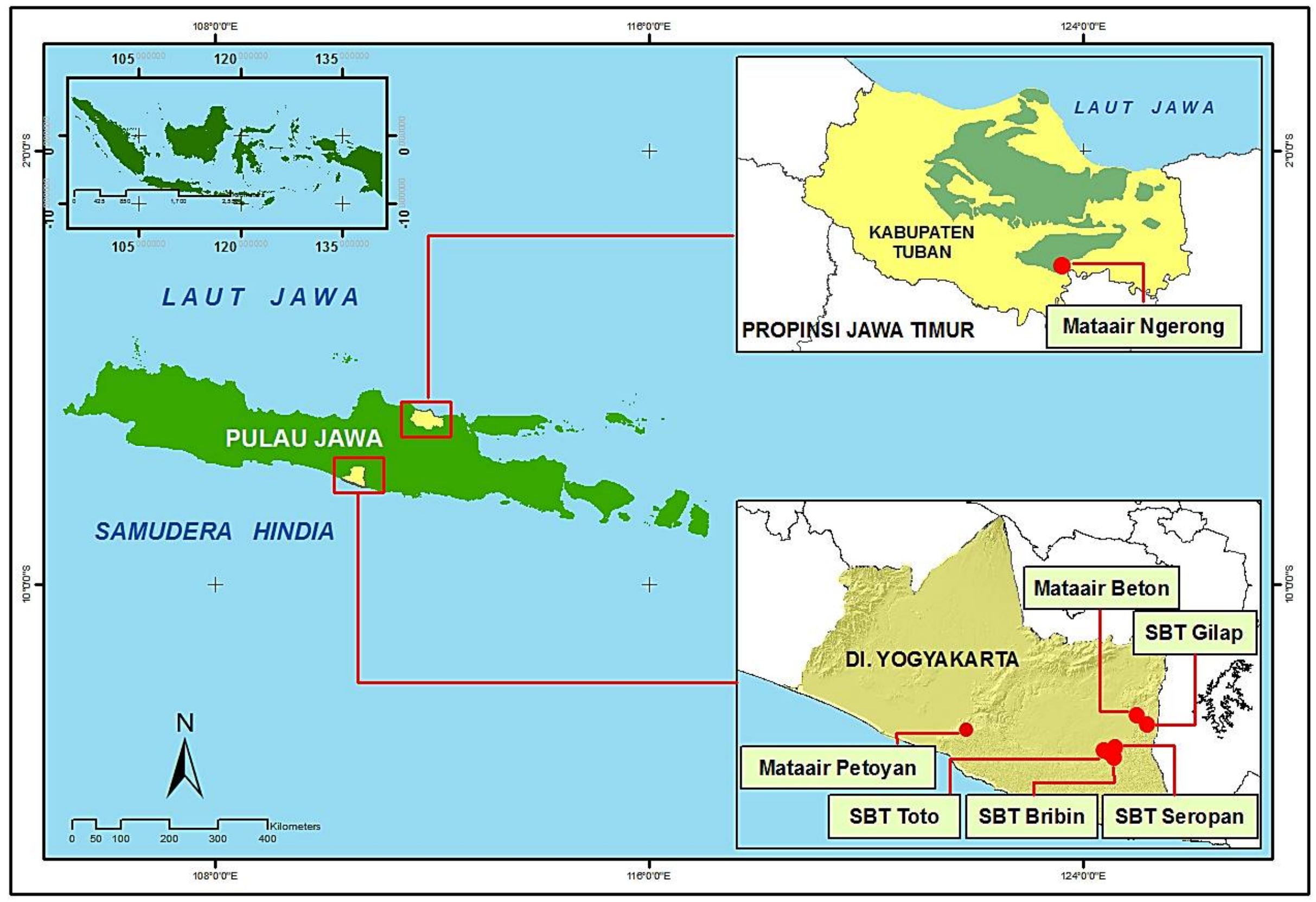




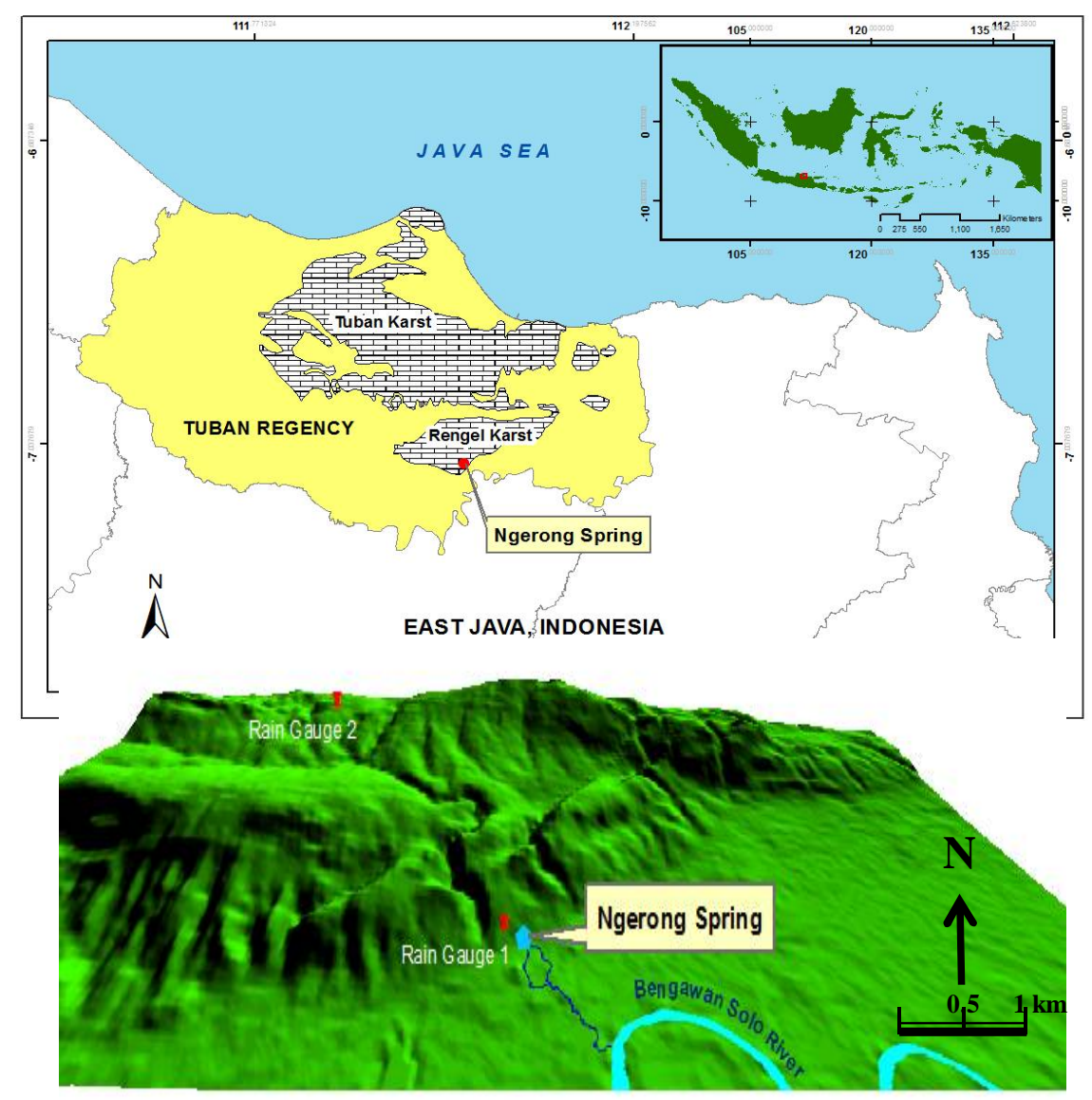

\section{Juni 2014, Debit \\ kecil, kondisi air jernih}

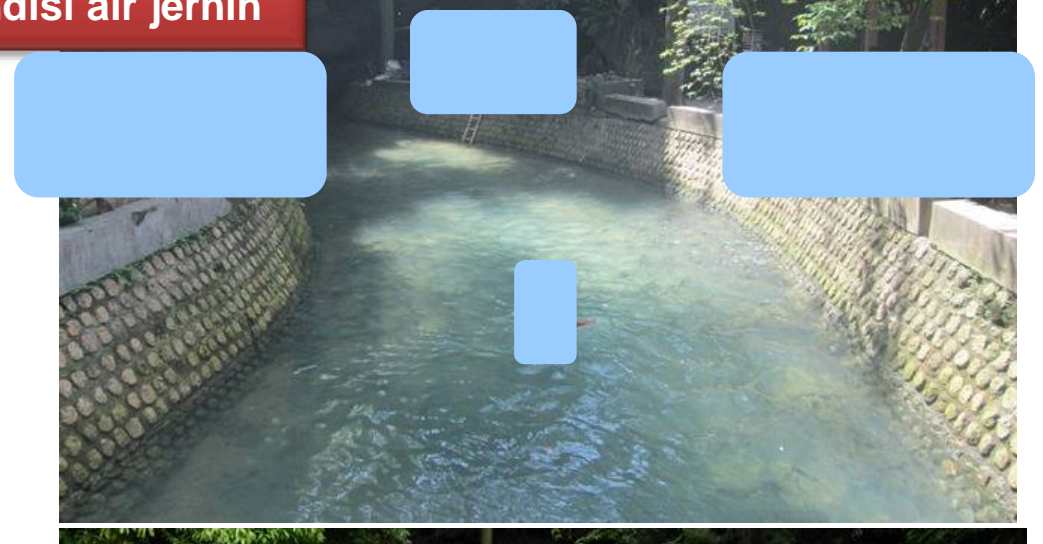

25 Januari 2013, Debit kecil, kondisi air agak keruh

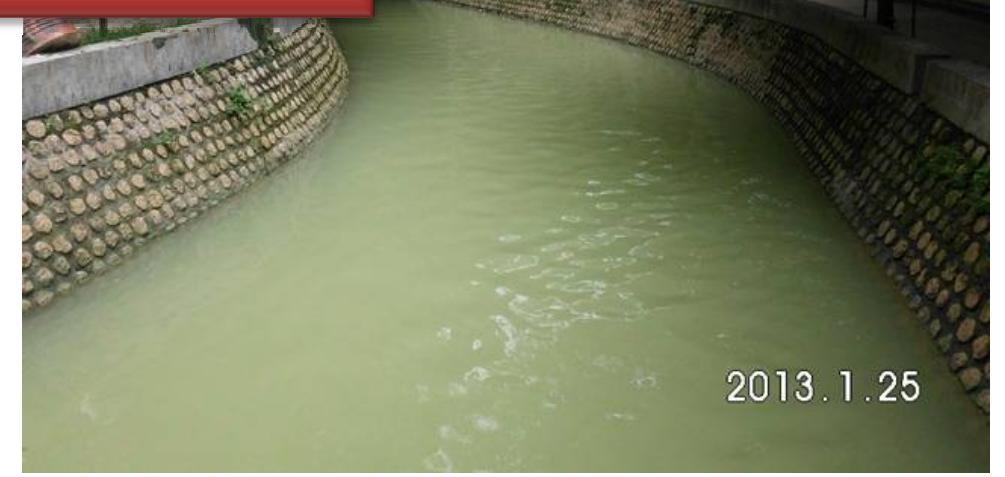

8 Maret 2014, Debit besar, kondisi air sangat keruh
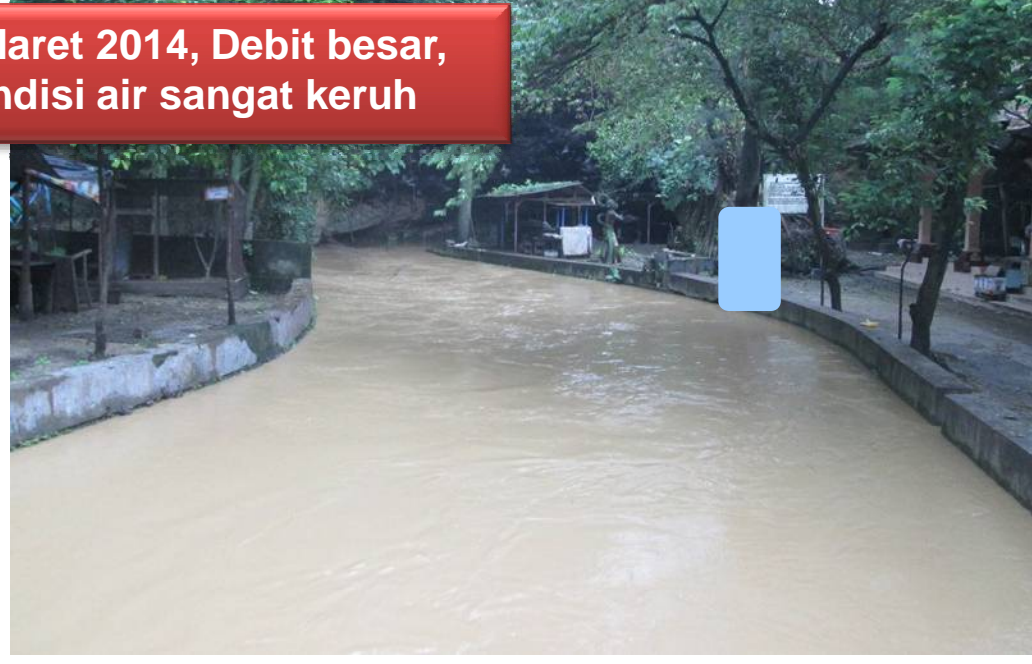

6 Maret 2014, Debit

Sedang, kondisi air keruh

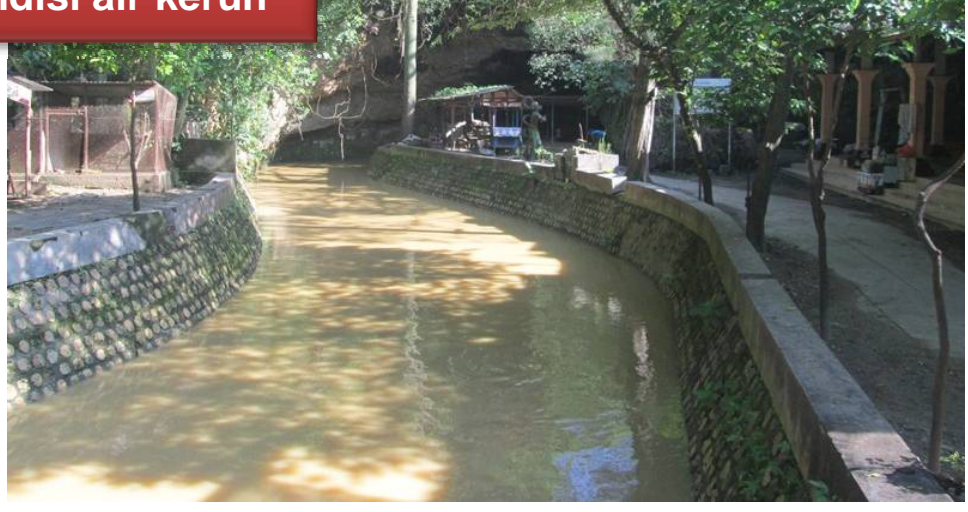




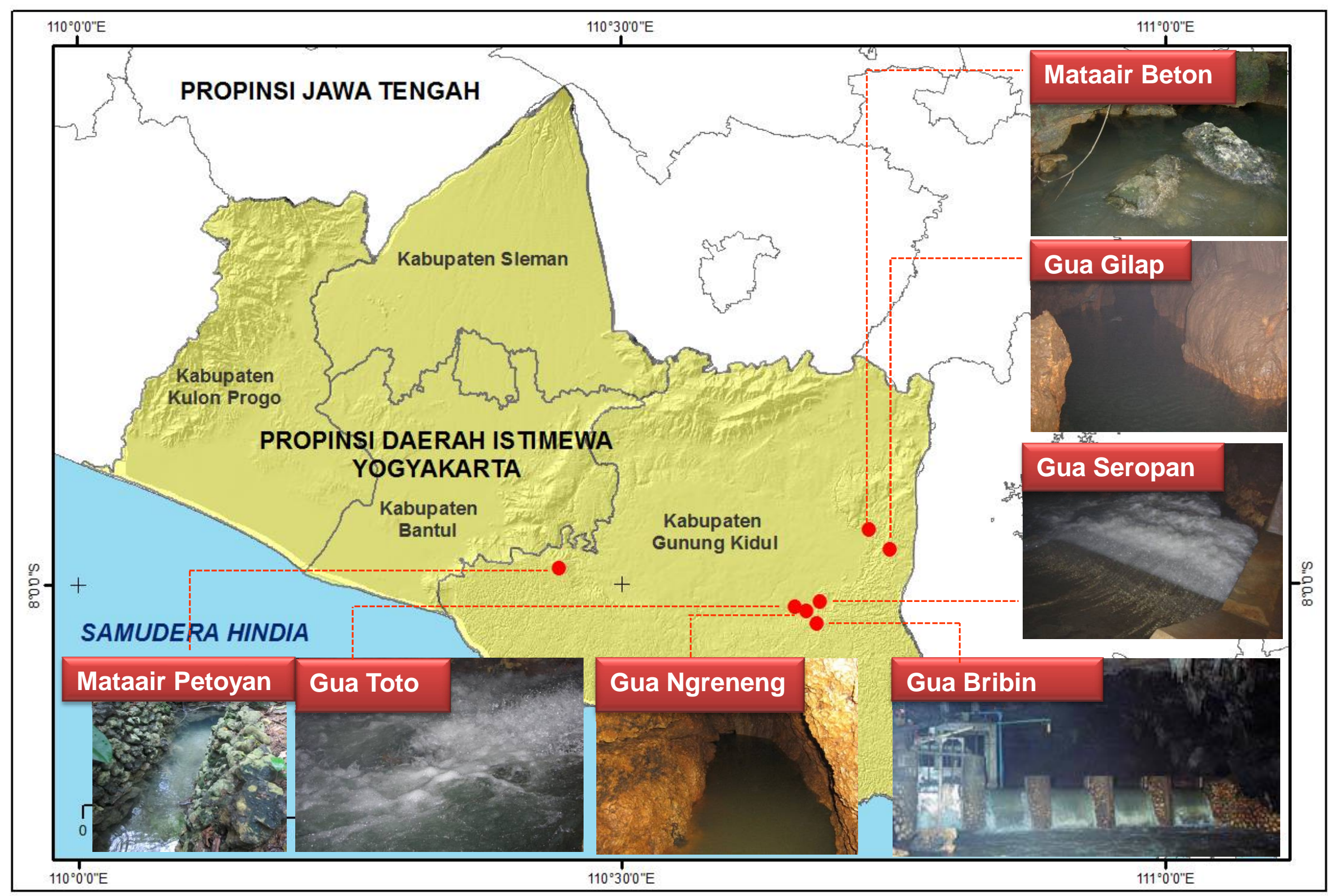




\section{Metode Penelitian}

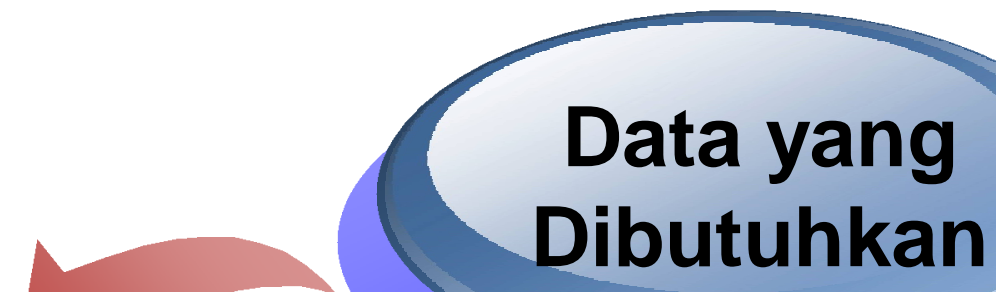

\section{Data Tinggi Muka Air (TMA)}

Direkam secara time series dg Interval $\mathbf{1 5}$ dan $\mathbf{3 0}$ menit menggunakan Hobo Water Level
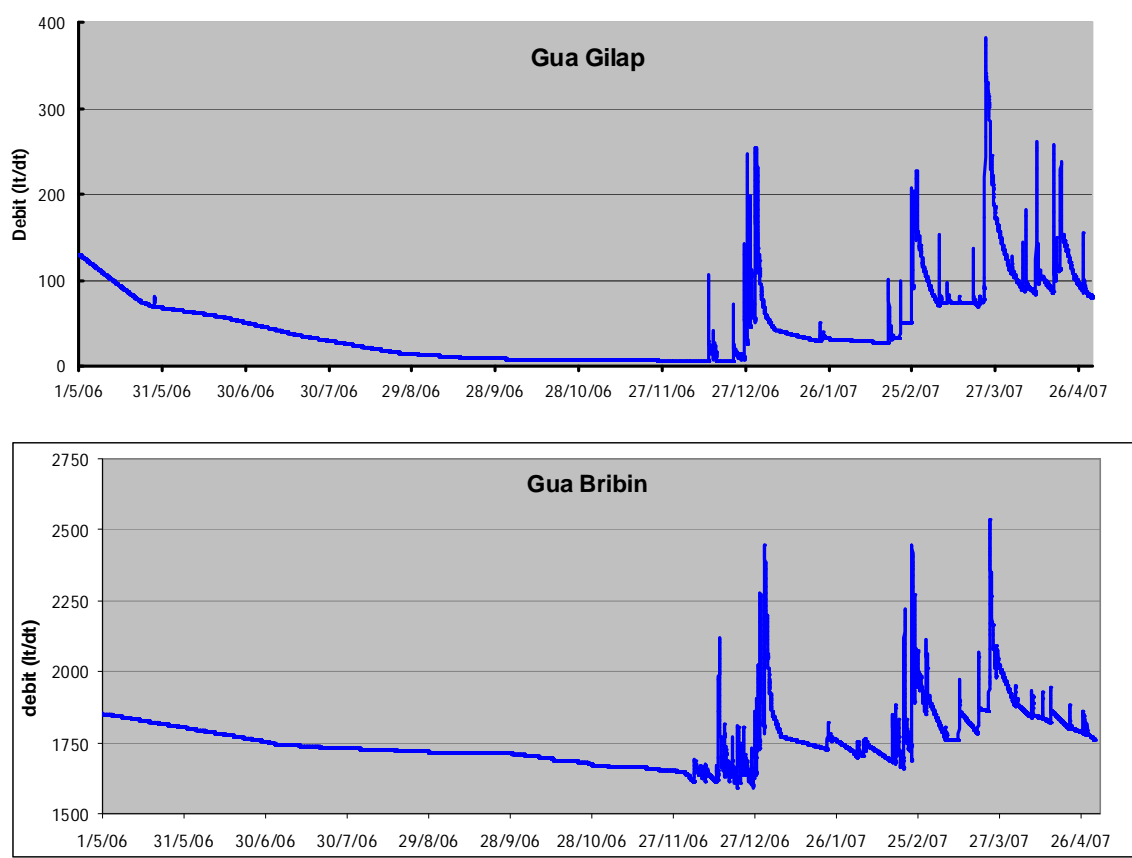

\section{Pengukuran Debit}

- Sudden Injection

- Velocity Area Methods

- Current Meter

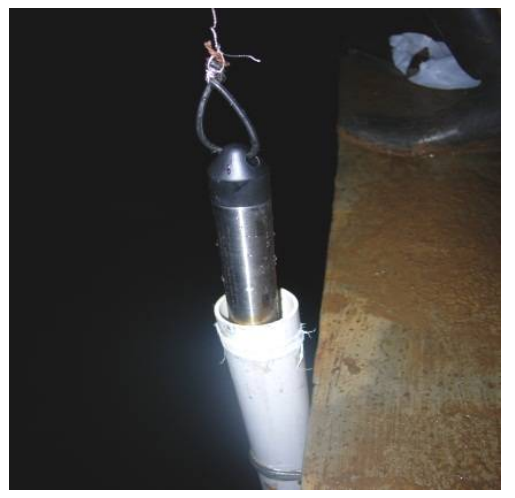

onset

\section{I010}

Water Level Logger-Titanium

0 to $4 \mathrm{~m} 10$ to $13 \mathrm{ft}$

P/N: U20-001-04-TI S/N: 9738917 


\section{Tahapan Analisis Penelitian}
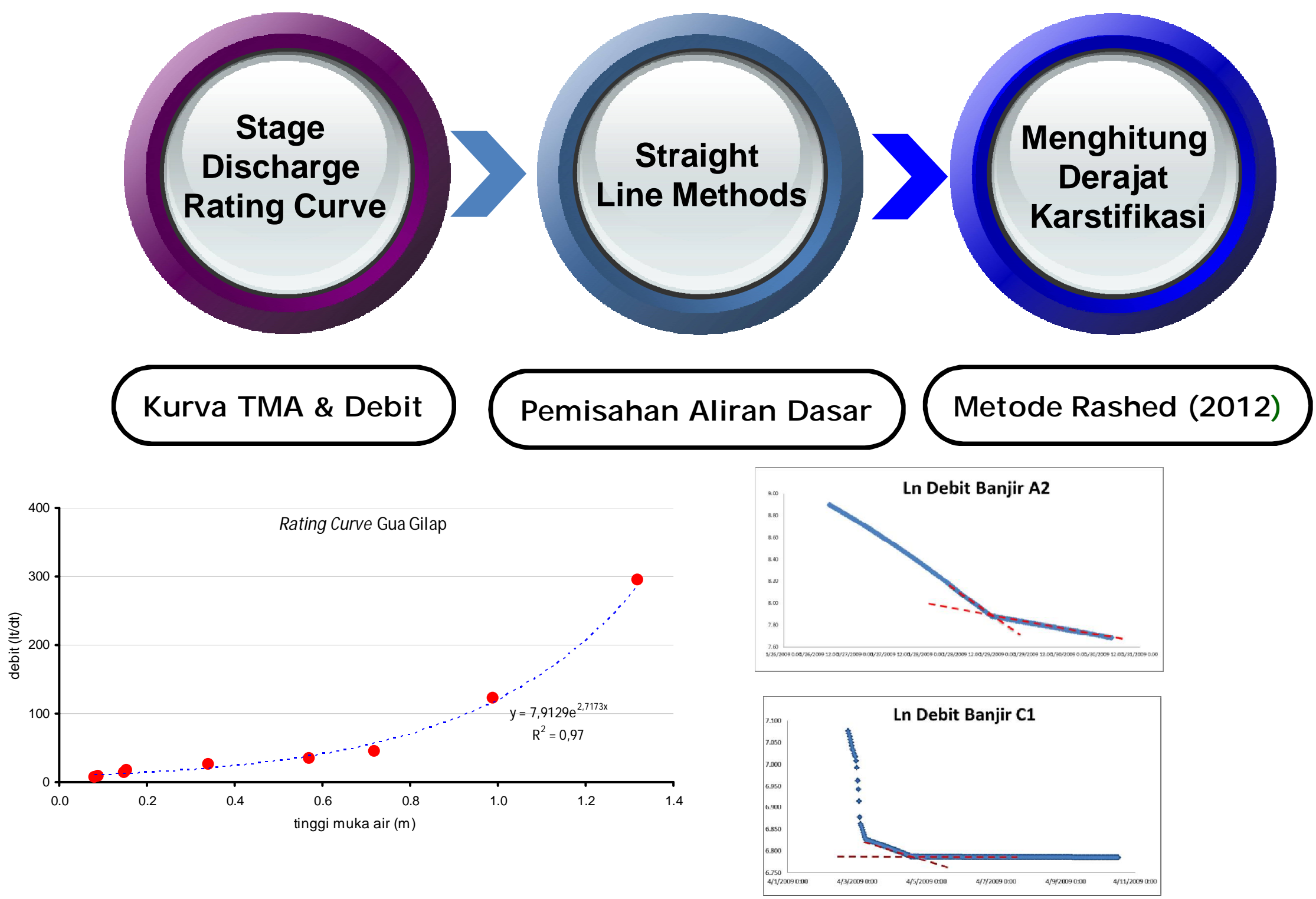


\section{Karakteristik Umum}

Debit Terendah $=$ Mataair Petoyan

Debit Banjir Tertinggi $=$ Mataair Beton

Time to peak tercepat $=$ SBT Gilap $(3 \mathrm{Jam})$

Time to baseflow terlama $=$ SBT Toto dan Seropan

$\%$ baseflow paling besar $=$ SBT Bribin 


\section{Hidrograf Banjir}

\section{Seropan}

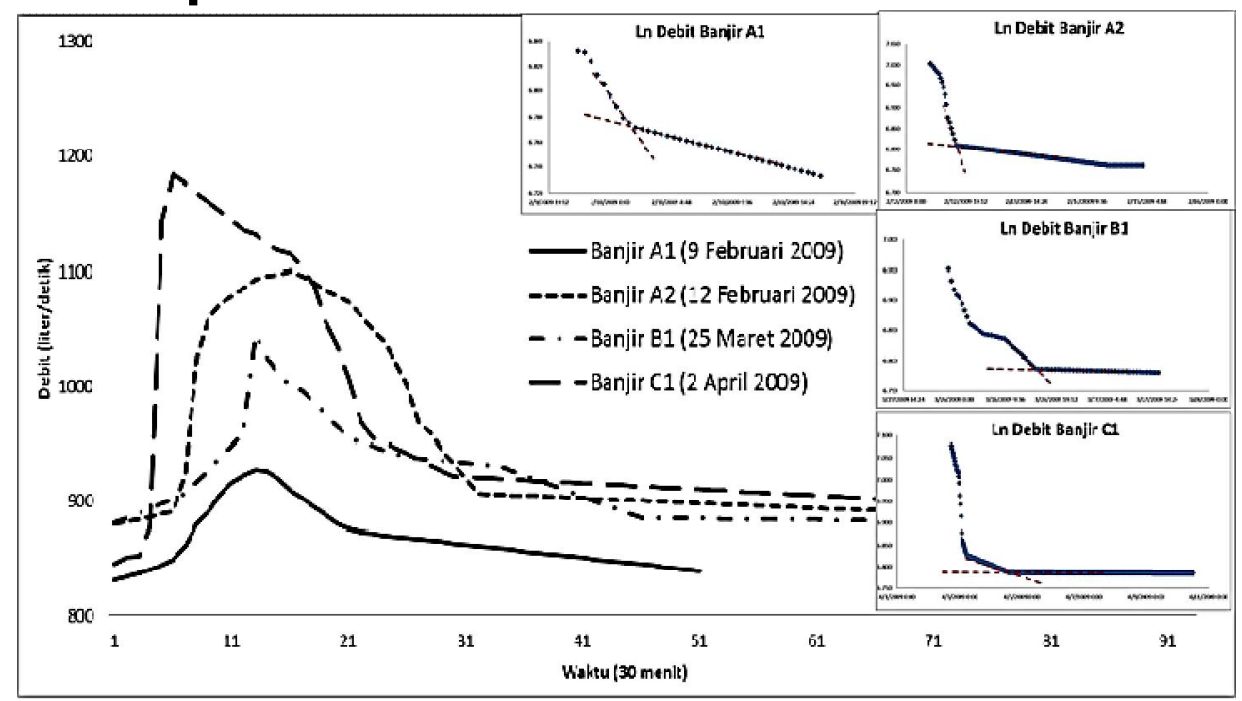

\section{Bribin}

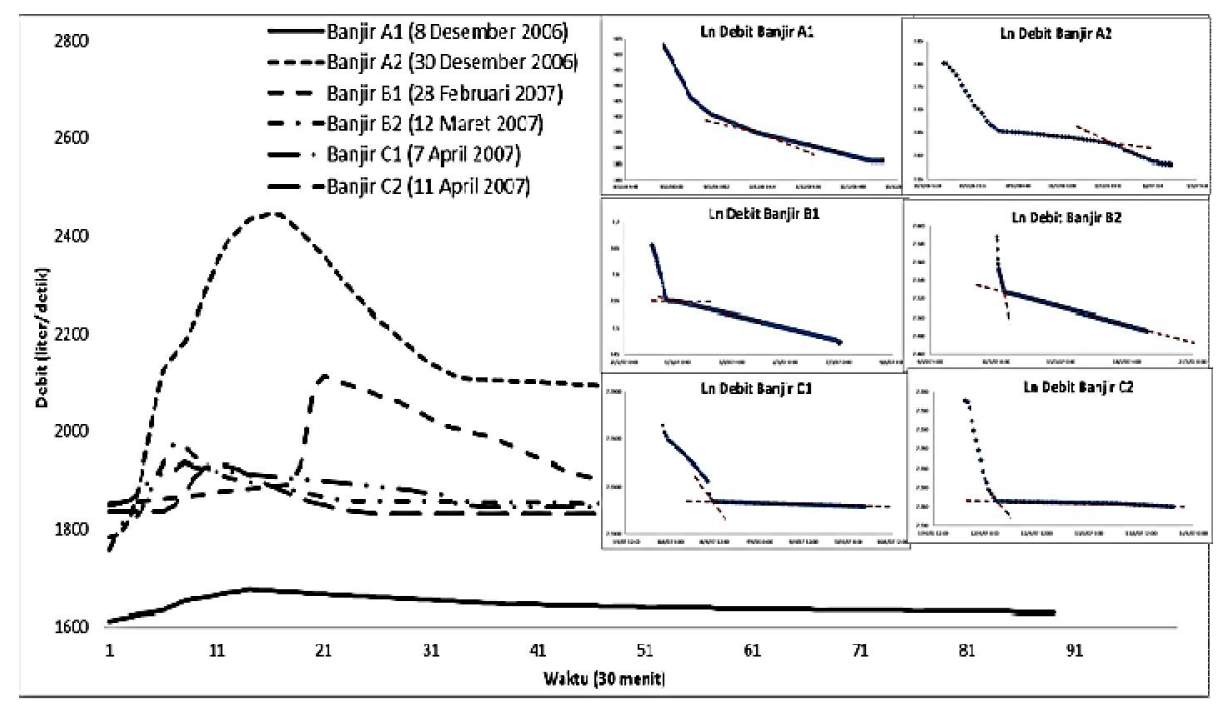

\section{Gilap}

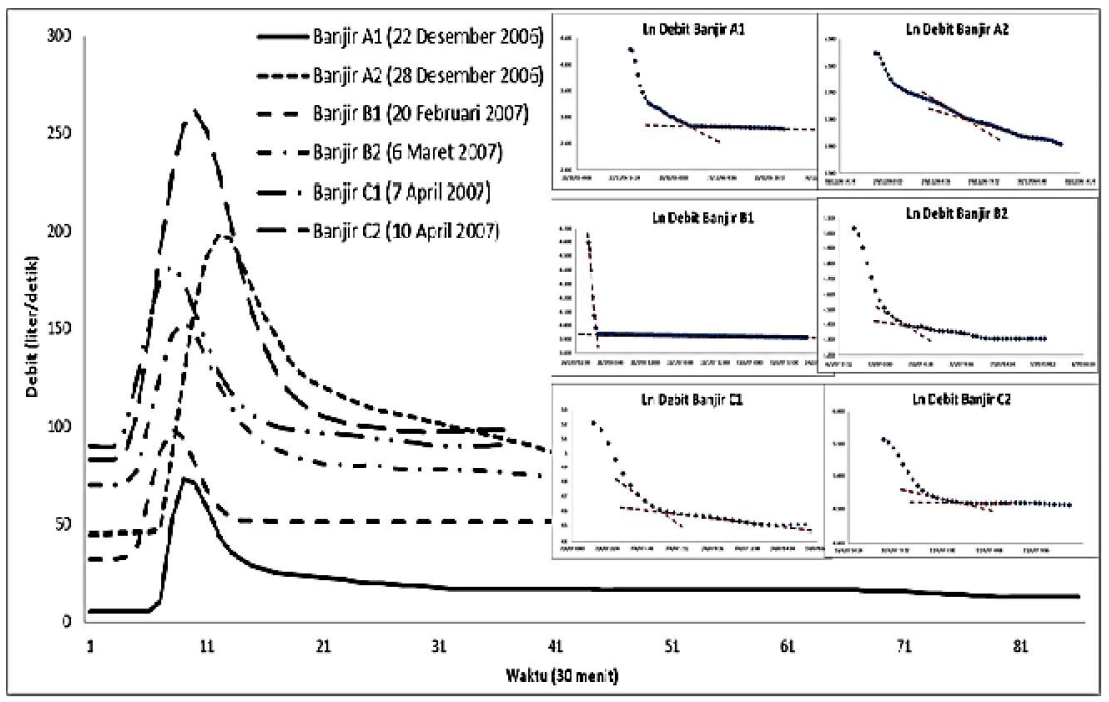

\section{Ngerong}

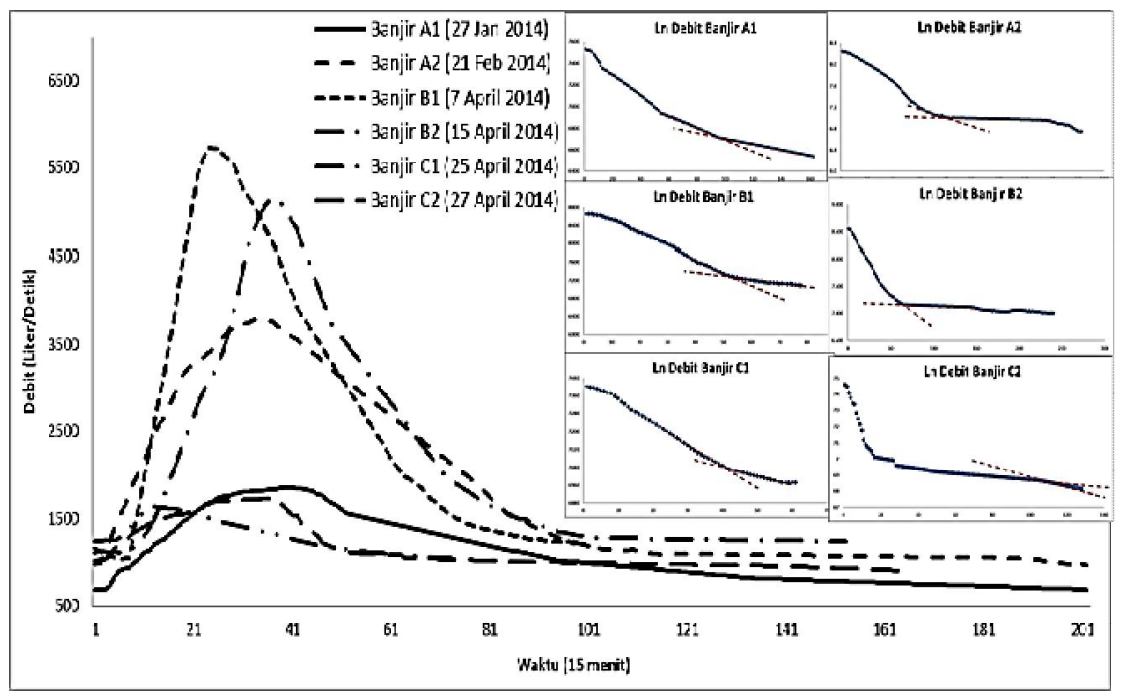




\section{Toto}

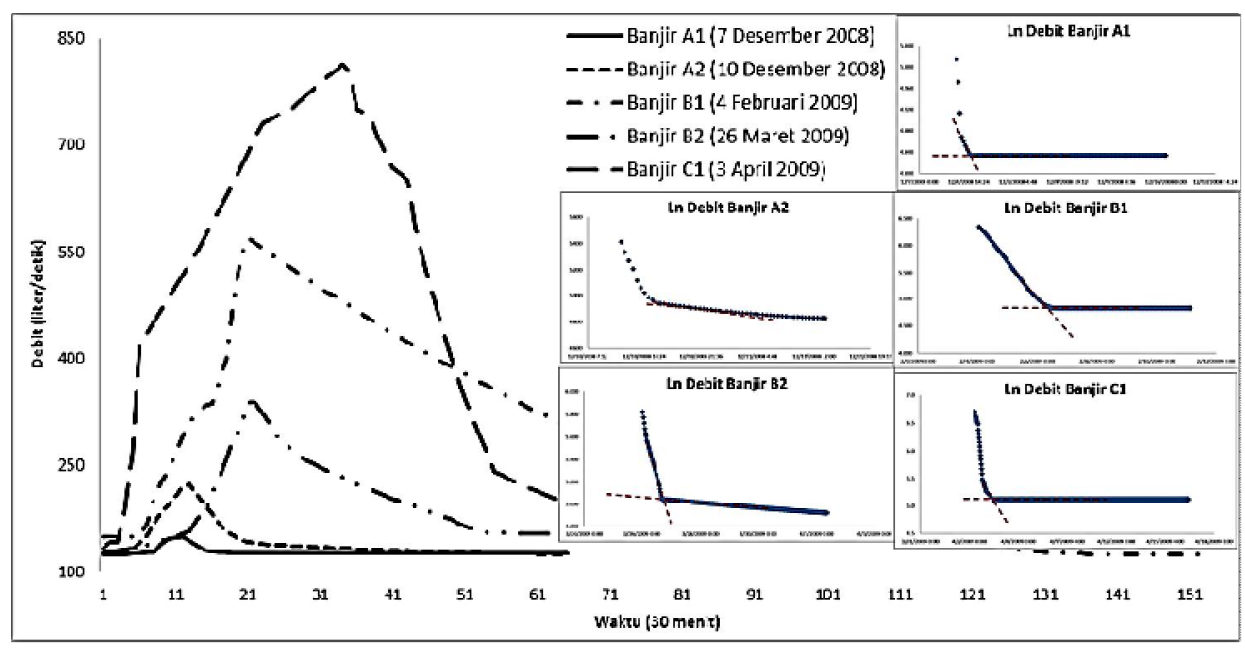

\section{Beton}

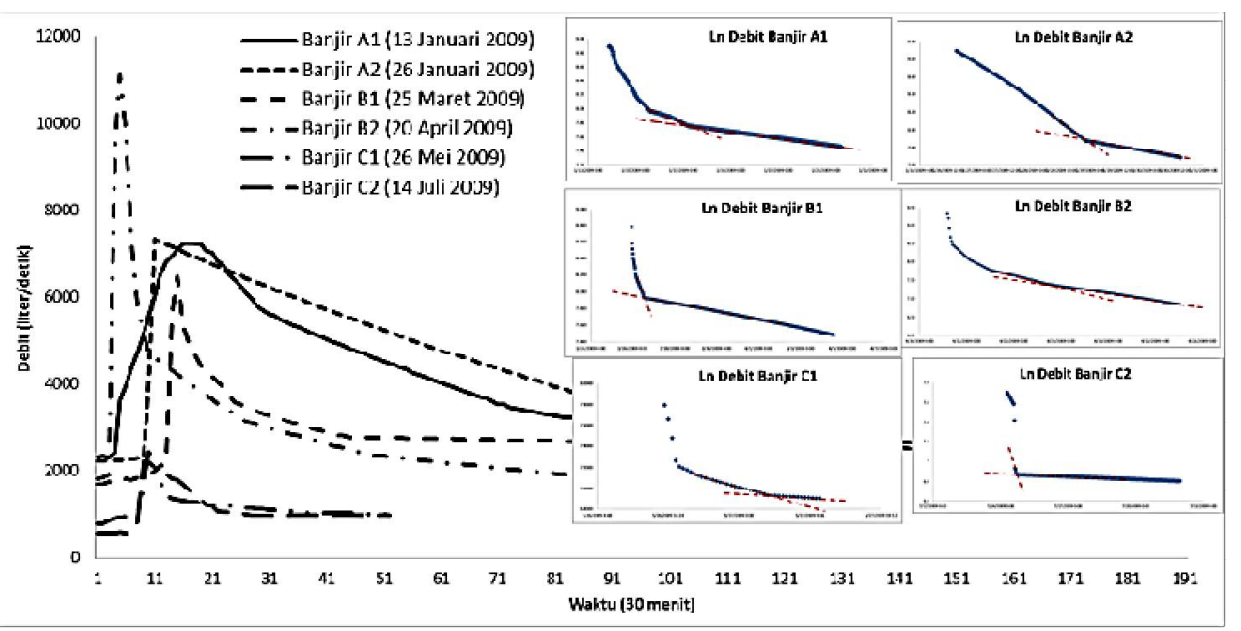

\section{Petoyan}

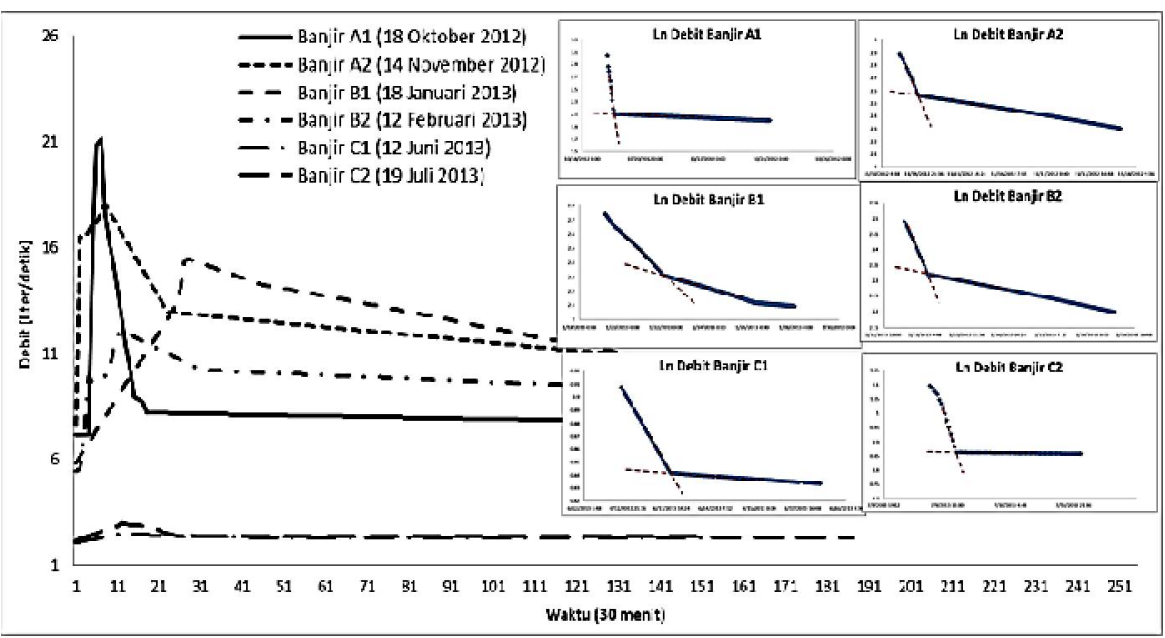

Ngreneng

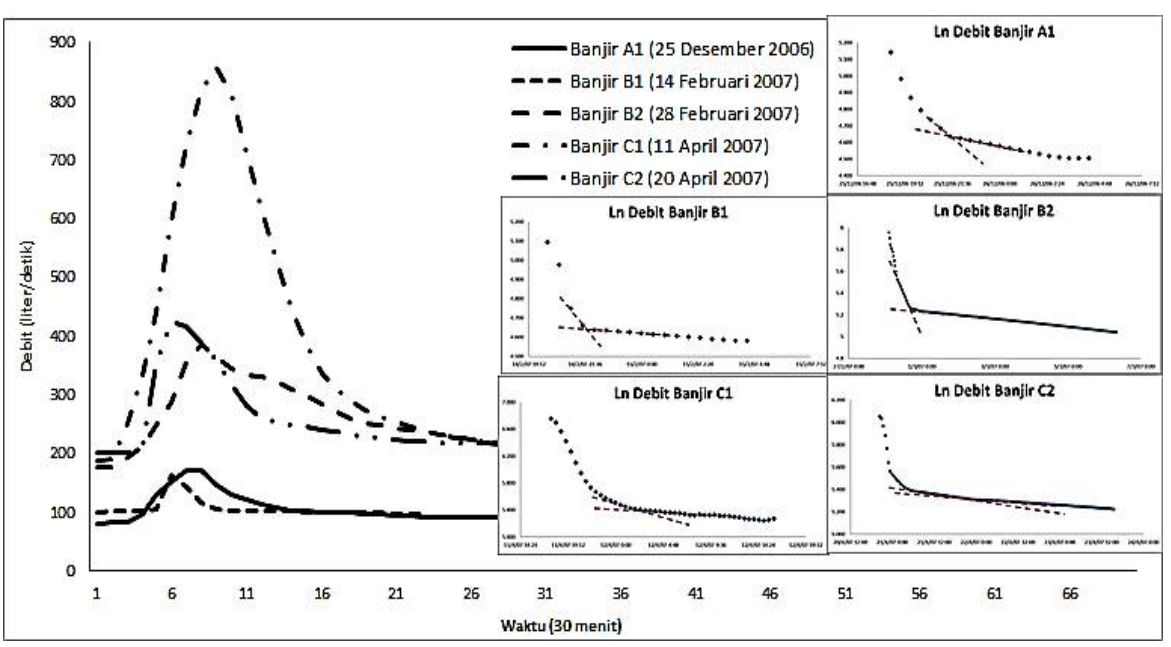




\section{Parameter Hidrograf Banjir}

\begin{tabular}{|c|c|c|c|c|c|c|c|c|c|c|}
\hline \multirow{2}{*}{ Mataair dan SBT } & \multirow{2}{*}{ Periode } & \multicolumn{3}{|c|}{ Debit (Q) liter/detik } & \multicolumn{3}{|c|}{ Rerata Waktu (Jam) } & \multicolumn{3}{|c|}{ \% Baseflow Musim Hujan } \\
\hline & & $Q \min$ & $Q \max$ & $Q$ mean & $\mathrm{Tp}$ & $\mathrm{Tb}$ & T event & Awal & Tengah & Akhir \\
\hline Mataair Beton & $\begin{array}{l}\text { Januari - September } \\
2009\end{array}$ & 505.9 & 11111.7 & 1555.7 & 12.9 & 193.4 & 154 & 48.22 & 51.77 & 46.94 \\
\hline Mataair Petoyan & $\begin{array}{l}\text { Oktober 2012- } \\
\text { Agustus } 2013\end{array}$ & 1.95 & 48.49 & 7.62 & 3.6 & 9.3 & 12.9 & 40.36 & 22.67 & 39.56 \\
\hline SBT Gilap & Mei 2006 - April 2007 & 3 & 380 & - & 3 & 36 & 37.56 & 52.78 & 55.68 & 72.12 \\
\hline SBT Ngreneng & Mei 2006 - April 2007 & 60 & 1905.3 & - & 4.5 & 16.8 & 56.12 & 45.10 & 48.75 & - \\
\hline SBT Seropan & $\begin{array}{l}\text { Februari - Agustus } \\
2009\end{array}$ & 812.4 & 1184.5 & 875.7 & 83.6 & 619.2 & 702.85 & - & 70.47 & 67.09 \\
\hline SBT Toto & $\begin{array}{l}\text { November 2008- } \\
\text { September } 2009\end{array}$ & 124.5 & 943.5 & 153.5 & 14.4 & 910 & 924.28 & 73.09 & 66.64 & 72.65 \\
\hline SBT Bribin & Mei 2006 - April 2007 & 1630 & 2520 & - & 5.5 & 36 & 41.45 & 88.79 & 87.13 & 97.27 \\
\hline SBT Ngerong & Januari - Juli 2014 & 580.2 & 6407.9 & 968.5 & 10.25 & 20.54 & 30.77 & 50.46 & 57.26 & 48.14 \\
\hline
\end{tabular}




\section{Menghitung Derajat Karstifikasi $\left(D_{k}\right)$}

Rumus MALIK VOJTKOVA (2012)

$Q_{t}=Q_{\mathrm{o}} \mathrm{e}^{-\alpha t} \quad \ldots \ldots$ resesi aliran diffuse (laminer)

$Q_{t}=Q_{\mathrm{o}}(1-\beta t) \quad \ldots . .$. resesi aliran conduit (turbulen)

Beberapa aliran laminar and turbulent bisa dijumpai pada satu mataair yang mencerminkan jenis perkembangan pelorongan di akuifer karst-nya 


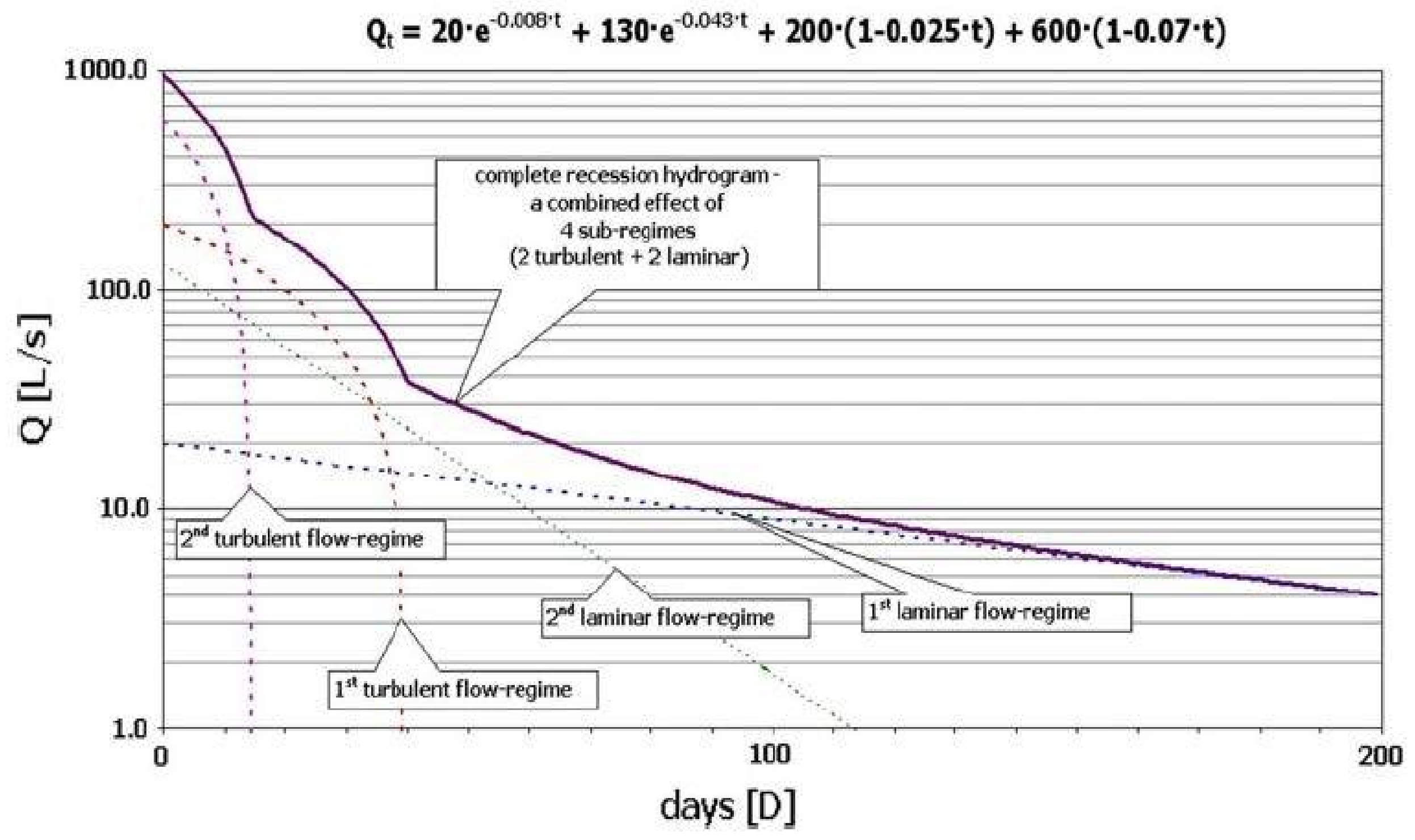

Kombinasi jenis aliran pada resesi banjir untuk penentuan perkembangan karst 


\begin{tabular}{|c|c|c|c|c|}
\hline $\begin{array}{l}\text { Karstification } \\
\text { degree }\end{array}$ & $\begin{array}{l}\text { Groundwater flow } \\
\text { sub-regimes type }\end{array}$ & $\begin{array}{l}\text { Characteristic } \\
\text { recession curve } \\
\text { equation }\end{array}$ & $\begin{array}{l}\text { Characteristics of } \\
\text { recession-curve } \\
\text { parameters }\end{array}$ & $\begin{array}{l}\text { Characteristics of karstification } \\
\text { degree }\end{array}$ \\
\hline 0.5 & \multirow{2}{*}{$\begin{array}{l}\text { Single laminar sub-regime, lower values } \\
\text { of } \alpha_{1}\end{array}$} & \multirow[t]{4}{*}{$Q_{t}=Q_{\mathrm{ol}} \mathrm{e}^{-\alpha 1 t}$} & $\alpha_{1}<0.001$ & \multirow{2}{*}{$\begin{array}{l}\text { Usually tectonic faults and shear zones } \\
\text { filled with crushed material, with high } \\
\text { buffering capability in relation to } \\
\text { discharge. Mainly deeper groundwater } \\
\text { circulation }\end{array}$} \\
\hline 1.0 & & & $\alpha_{1}=0.001-0.0025$ & \\
\hline 2.0 & \multirow{2}{*}{$\begin{array}{l}\text { Single laminar sub-regime, higher } \\
\text { values of } \alpha_{1}\end{array}$} & & $\alpha_{1}=0.0025-0.007$ & \multirow{2}{*}{$\begin{array}{l}\text { Tectonic faults filled with crushed } \\
\text { material with higher permeability and } \\
\text { lower buffering capability in relation } \\
\text { to discharge. In some cases deeper } \\
\text { groundwater circulation }\end{array}$} \\
\hline 2.3 & & & $\alpha_{1}>0.007$ & \\
\hline 2.5 & \multirow{3}{*}{$\begin{array}{l}\text { Combination of two or more sub- } \\
\text { regimes with merely laminar flow } \\
\text { characterised by different discharge } \\
\text { coefficients, lower values of } \alpha_{1} \text { and } \alpha_{2}\end{array}$} & \multirow[t]{6}{*}{$\begin{array}{l}Q_{t}=Q_{\mathrm{o} 1} \mathrm{e}^{-} \\
+Q_{\mathrm{o} 2} \mathrm{e}^{-\alpha 2 t}\end{array}$} & $\begin{array}{l}\alpha_{1}<0.0024 \text { and } \\
\alpha_{2}<0.033\end{array}$ & \multirow{3}{*}{$\begin{array}{l}\text { Aquifer with dense, prevailingly regular } \\
\text { fissure network, with majority of } \\
\text { micro-fissures and small fissures. } \\
\text { Increase of values } \alpha_{1} \text { and } \alpha_{2} \\
\text { accompanies increasing permeability } \\
\text { and also higher heterogeneity of } \\
\text { fissured rock environment }\end{array}$} \\
\hline 2.7 & & & $\begin{array}{c}\alpha_{1}<0.0024 \text { or } \\
\alpha_{2}<0.033\end{array}$ & \\
\hline 3.0 & & & $\begin{array}{c}\alpha_{1}=0.0024-0.0045 \\
\alpha_{2}=0.033-0.067\end{array}$ & \\
\hline 3.5 & \multirow{3}{*}{$\begin{array}{l}\text { Combination of two or more sub- } \\
\text { regimes with merely laminar flow } \\
\text { characterised by different discharge } \\
\text { coefficients, higher values of } \alpha_{1} \text { and } \alpha_{2}\end{array}$} & & $\begin{array}{l}\alpha_{1}=0.0024-0.0043 \\
\text { and } \\
\alpha_{2}=0.060-0.16\end{array}$ & \multirow{3}{*}{$\begin{array}{l}\text { Aquifer with irregularly developed } \\
\text { fissure network, with majority of open } \\
\text { macrofissures, also with possible } \\
\text { presence of karst conduits of limited } \\
\text { extent. In extreme cases, even short- } \\
\text { term turbulent flow might occur in this } \\
\text { type of rock environment }\end{array}$} \\
\hline 3.7 & & & $\begin{array}{l}\alpha_{1}>0.0043 \text { and } \\
\alpha_{2}<0.060\end{array}$ & \\
\hline 4.0 & & & $\begin{array}{l}\alpha_{1}=0.0041-0.018 \\
\text { and } \\
\alpha_{2}=0.055-0.16\end{array}$ & \\
\hline 4.3 & \multirow{3}{*}{$\begin{array}{l}\text { Discharge hydrogram is composed of a } \\
\text { sub-regime with turbulent flow and a } \\
\text { sub-regime with laminar flow. } \\
\text { Substantial role in groundwater } \\
\text { discharge plays the sub-regime with } \\
\text { laminar flow }\end{array}$} & \multirow{3}{*}{$\begin{array}{l}Q_{t}=Q_{\mathrm{o} 1} \mathrm{e}^{-} \\
\quad Q_{\mathrm{o} 4}(1- \\
\left.\beta_{1} t\right)\end{array}$} & $\begin{array}{c}\alpha_{1}>0.018 \text { or } \\
\alpha_{2}>0.16\end{array}$ & \multirow{3}{*}{$\begin{array}{l}\text { Aquifer with anticipated existence of } \\
\text { crushed water-bearing zone (e.g., fault } \\
\text { zone) or by dense network of open } \\
\text { small fissures in combination with } \\
\text { simple, partly (or occasionally) } \\
\text { phreatic conduit system of } \\
\text { considerable extent (e.g., with open } \\
\text { karstified fault in the vadose zone) }\end{array}$} \\
\hline 4.7 & & & $\begin{array}{l}\alpha_{1}>0.018 \text { and } \\
\alpha_{2}>0.16\end{array}$ & \\
\hline 5.0 & & & $\beta$ and $\alpha$ low values & \\
\hline 5.5 & $\begin{array}{l}\text { Complex discharge regime, a } \\
\text { combination of one sub-regime with } \\
\text { turbulent flow and two sub-regimes } \\
\text { with laminar groundwater flow. } \\
\text { Discharge sub-regime with turbulent } \\
\text { flow is of short-term influence in } \\
\text { comparison with overall groundwater } \\
\text { discharge }\end{array}$ & $\begin{array}{l}Q_{t}=Q_{\mathrm{o} 1} \mathrm{e}^{-} \\
\alpha 1 t+Q_{\mathrm{o} 2} \mathrm{e}^{-} \\
\alpha 2 t+Q_{\mathrm{o} 4}(1- \\
\left.\beta_{1} t\right)\end{array}$ & $\begin{array}{l}\alpha_{1}>0 \text { and } \alpha_{2}>0 \\
\text { and } \beta_{1}>0\end{array}$ & $\begin{array}{l}\text { Extensive disruption and disintegration } \\
\text { of rock environment, with majority of } \\
\text { open, medium size, both not karstified } \\
\text { and karstified fissures in the phreatic } \\
\text { zone of the fissure karst aquifer } \\
\text { (according to } \alpha_{1} \text { ) and with smaller } \\
\text { influence of connected conduits } \\
\text { (groundwater of large karstic channels, } \\
\text { according to } \beta_{1} \text { ) }\end{array}$ \\
\hline 6.0 & $\begin{array}{l}\text { Very complex discharge regime, a } \\
\text { combination of two sub-regimes with } \\
\text { turbulent flow and two sub-regimes } \\
\text { with laminar groundwater flow. } \\
\text { Discharge sub-regimes with turbulent } \\
\text { flow are of short-term influence in } \\
\text { comparison with overall groundwater } \\
\text { discharge }\end{array}$ & $\begin{array}{l}Q_{t}=Q_{\mathrm{o} 1} \mathrm{e}^{-} \\
\alpha 2 t+Q_{\mathrm{o} 2} \mathrm{e}^{-} \\
+Q_{\mathrm{o} 4}(1- \\
\left.\beta_{1} t\right)+Q_{\mathrm{o} 5}(1- \\
\left.\beta_{2} t\right)\end{array}$ & $\begin{array}{l}\beta_{2}, \beta_{1} \text { and } \alpha_{1}, \alpha_{2} \text { high } \\
\quad \text { values }\end{array}$ & $\begin{array}{l}\text { Extensive disruption and disintegration } \\
\text { of rock environment, with majority of } \\
\text { open, medium size, both not karstified } \\
\text { and karstified fissures in the phreatic } \\
\text { zone of the fissure karst aquifer } \\
\text { (according to } \alpha_{1} \text { ) and with smaller } \\
\text { influence of connected conduits } \\
\text { (groundwater of large karstic channels, } \\
\text { according } \beta_{1} \text { and } \beta_{2} \text { ) }\end{array}$ \\
\hline
\end{tabular}




\begin{tabular}{lllll}
\hline $\begin{array}{l}\text { Karstification } \\
\text { degree }\end{array}$ & $\begin{array}{l}\text { Groundwater flow } \\
\text { sub-regimes type }\end{array}$ & $\begin{array}{l}\text { Characteristic } \\
\text { recession curve } \\
\text { equation }\end{array}$ & $\begin{array}{l}\text { Characteristics of } \\
\text { recession-curve } \\
\text { parameters }\end{array}$ & $\begin{array}{l}\text { Characteristics of karstification } \\
\text { degree }\end{array}$ \\
& & pars
\end{tabular}

7.0 Discharge regime is a combination of one sub-regime with laminar flow with two to three sub-regimes with turbulent flow. Substantial role in groundwater discharge plays the subregime with laminar flow

Discharge regime is a combination of a sub-regime with laminar flow with two to three sub-regimes with turbulent flow. Substantial role in groundwater discharge is played by sub-regimes with turbulent flow. Sub-regime with laminar flow is less significant

Groundwater flow regime is represented merely by turbulent flow, with only one turbulent flow sub-regime present, which represents turbulent circulation in channel systems (conduits) without hydraulic connection to the groundwater in adjacent rock blocks. Groundwater circulation is mostly connected to vadose zone

Groundwater flow regime is represented merely by turbulent flow, consisting of two turbulent flow sub-regimes. These represent turbulent circulation in channel systems (conduits) without hydraulic connection to the groundwater in adjacent rock blocks Groundwater circulation is mostly connected to vadose zone

Complex turbulent flow regime of groundwater discharge, consisting of three different turbulent flow subregimes. Probability of a very complex groundwater circulation by occasiona flows in the vadose zone. Documented only in perennial flows

$Q_{t}=Q_{\mathrm{o} 1} \mathrm{e}^{-}$ ${ }^{\alpha 1 t}+Q_{\mathrm{o} 4}(1-$ $\left.\beta_{1} t\right)+Q_{\mathrm{o} 5}(1-$ $\left.\beta_{2} t\right)+Q_{\mathrm{o} 6}(1-$ $\left.\beta_{3} t\right)$

\section{$\beta_{3}, \beta_{2}, \beta_{1}$ and $\alpha$ high} values, $\beta_{1}>\beta_{2}$

\section{$\beta_{3}, \beta_{2}, \beta_{1}$ and $\alpha$ high values}

$$
\begin{array}{cc}
Q_{t}=Q_{\mathrm{o} 4}(1- & \alpha_{1} ; \alpha_{2}=0 \text { and } \\
\left.\beta_{1} t\right) & \beta_{1}>0
\end{array}
$$

$Q_{t}=Q_{\mathrm{o} 4}(1-$ $\left.\beta_{1} t\right)+Q_{05}(1-$ $\beta_{2} t$

$\beta_{1}, \beta_{2}$ low values

$$
\begin{aligned}
& \left.\beta_{1} t\right)+Q_{\mathrm{o} 5}(1- \\
& \left.\beta_{2} t\right)+Q_{\mathrm{o} 6}(1- \\
& \left.\beta_{3} t\right)
\end{aligned}
$$

$\beta_{1}, \beta_{2}$ and $\beta_{3}$ high values

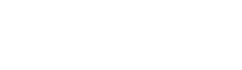

Developed karstification of the aquifer, formed by large open tectonic faults and karstic channels, as well as by significant portion of karstified and non-karstified fissures and microfissures in rock blocks, generating phreatic zone with karstic groundwater table

Highly developed karstification of the aquifer, formed by large open conduits (karst channels). Presence of open active small fissures and micro-fissures is reduced. Circulation of substantial part of groundwater is mainly via preferred pathways of channel systems. Phreatic zone is missing or its role is insignificant

Karstic aquifer with well-developed conduit system, without any significant connection to open phreatic fissure systems in adjacent rock blocks. Extensively developed conduit system can ensure permanent groundwater replenishment

Karstic aquifer with well-developed conduit systems of karstic groundwater pathways, without any significant connection to open phreatic fissure systems in adjacent rock blocks. Replenishment of groundwater resources can still be ensured by extensively developed conduit system

Karstic aquifer with extensive conduit system, without any significant connection to open phreatic fissure systems in adjacent rock blocks. In its spatial extent, the conduit system is bound only to the vadose zone, without enabling permanent groundwater replenishment 
Banjir 30 Desember 2006

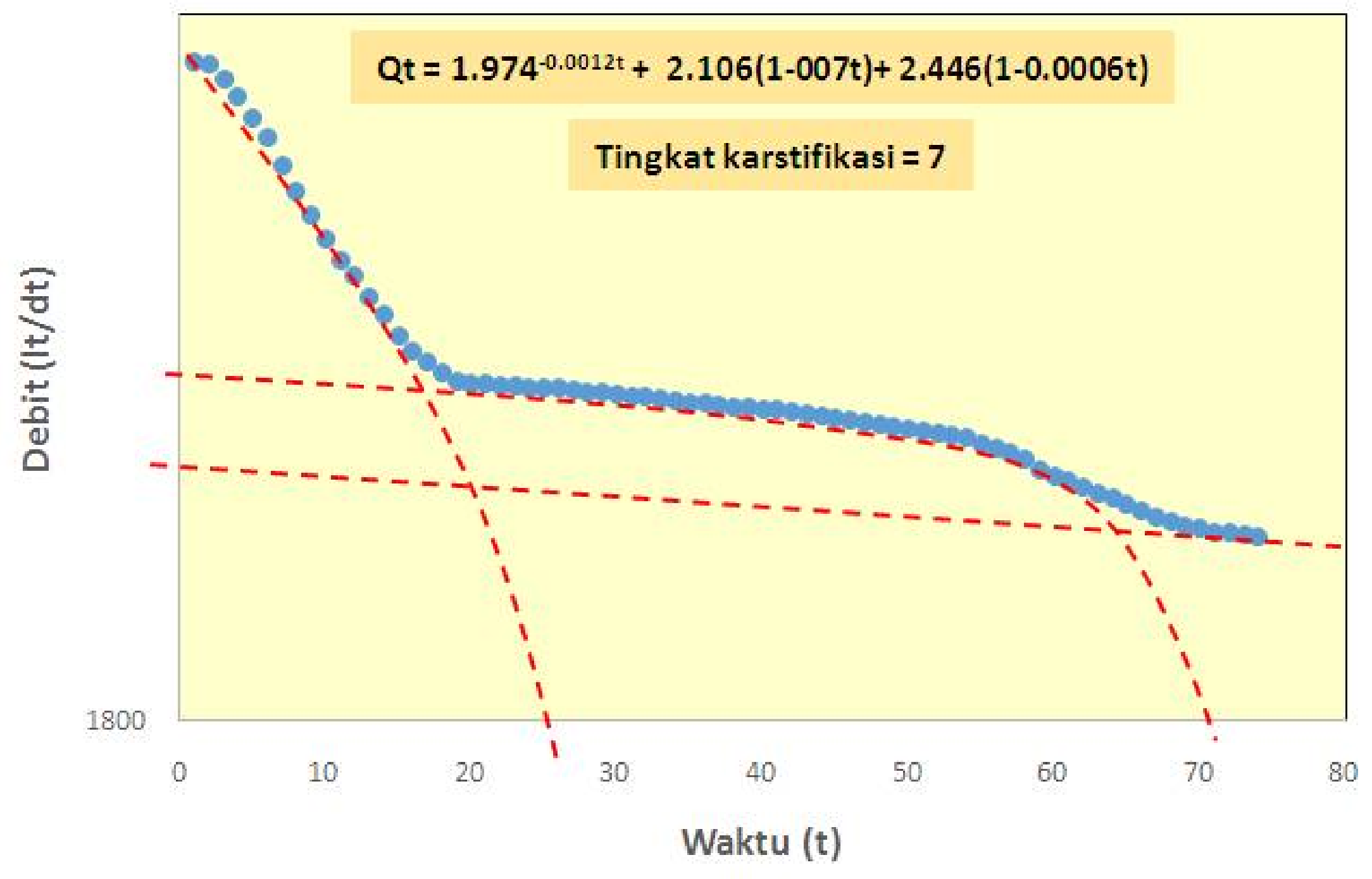

Jika karst sudah berkembang dewasa-tua (G. Bribin) 
15 April 2014

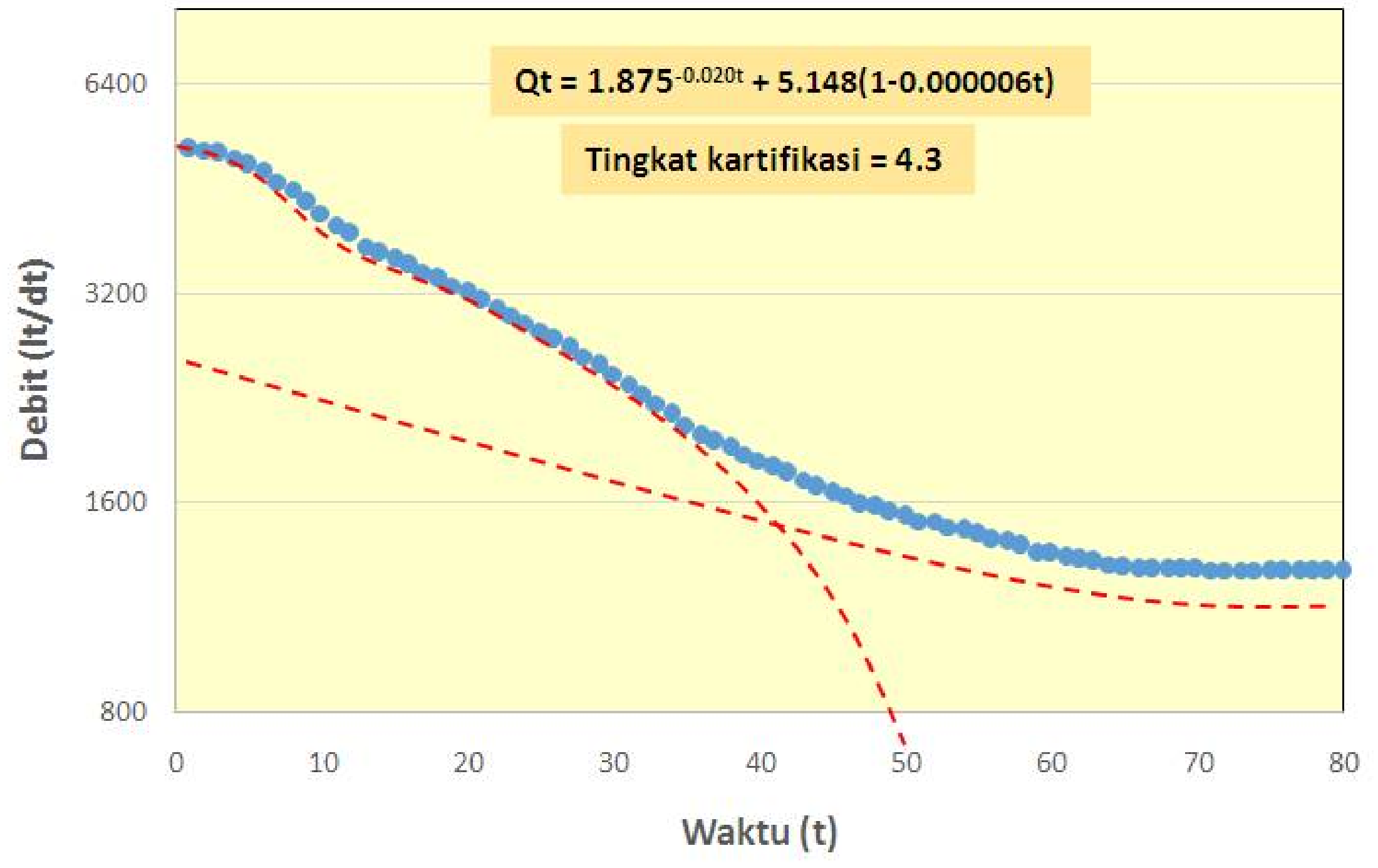

Jika karst muda menuju dewasa (G. Ngerong-Tuban) 


\section{Banjir 10 Februari 2014}

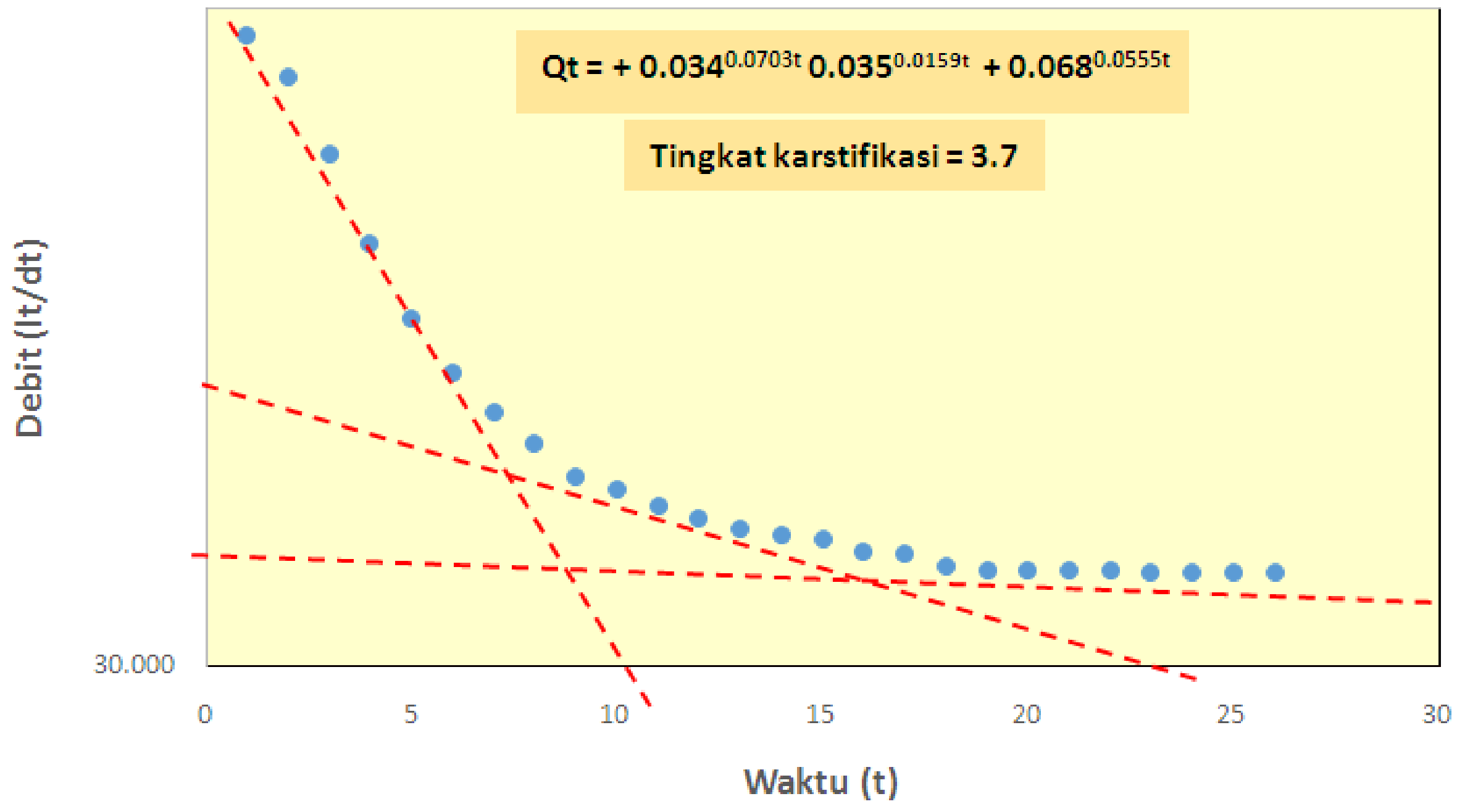

Jika karst muda (M ataair Petoyan) 


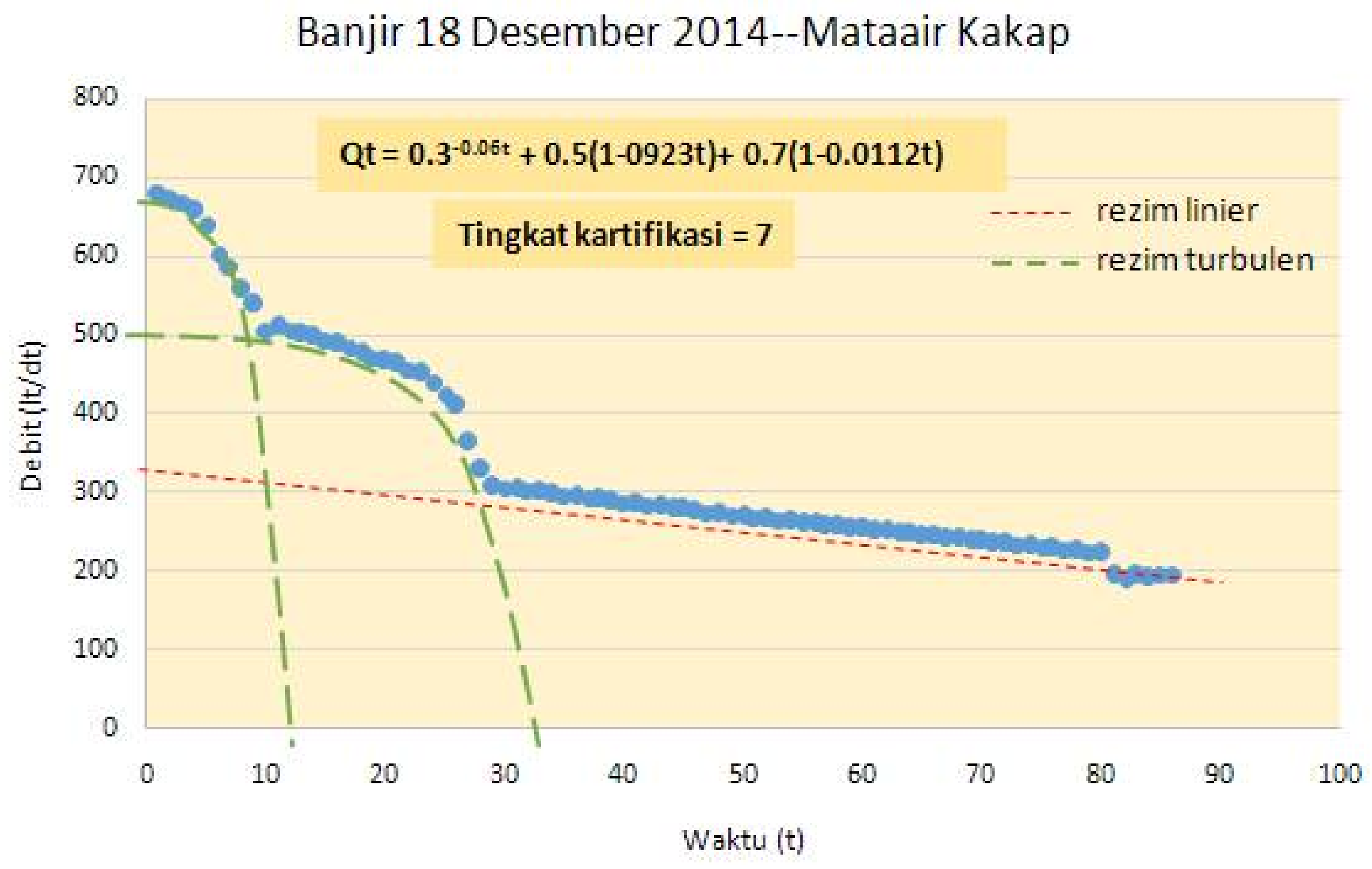




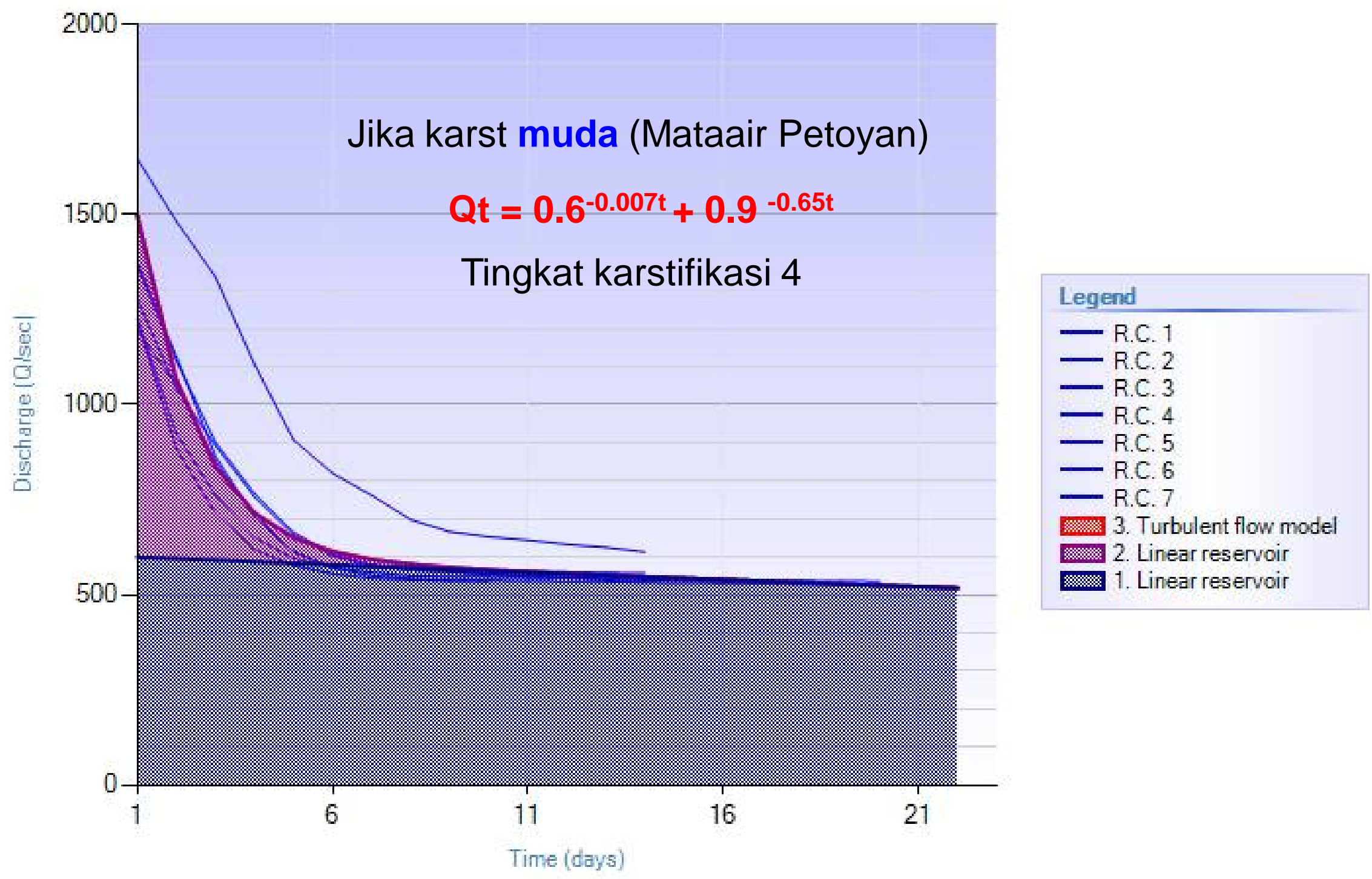




\begin{tabular}{|c|c|c|}
\hline $\begin{array}{c}\text { Mataair dan } \\
\text { SBT }\end{array}$ & $\begin{array}{c}\text { Derajat } \\
\text { karstifikasi }\end{array}$ & Rumus kurva resesi \\
\hline Mataair Beton & 6,6 & $Q t=2.757-0.009 t+3.372(1-006 t)+6.478(1-0.0005 t)$ \\
\hline Mataair Petoyan & 3,7 & $Q t=0.031^{0.0025 t}+0.032^{0.030 t}+0.034^{0.027 t}$ \\
\hline SBT Gilap & 5,8 & $Q t=0.103^{-0.0256 t}+0.183(1-0.145 t)$ \\
\hline SBT Ngreneng & 6,0 & $Q t=0.191^{0.0019 t}+0.260(1-0.851 t)+0.385(1-0.099 t)$ \\
\hline SBT Seropan & 5,2 & $Q t=0.218^{0.0045 t}+0.244^{0.0186 t}+0.424(1-0.0365 t)$ \\
\hline SBT Toto & 5,0 & $Q t=1.447^{-0.009 t}+1.639(1-0.000019 t)$ \\
\hline SBT Bribin & 7,7 & $Q t=1.847^{-0.0007 t}+1.911(1-0007 t)+1.936(1-0.0028 t)$ \\
\hline SBT Ngerong & 4,8 & $Q t=1.447^{-0.009 t}+1.639(1-0.000019 t)$ \\
\hline Sumbersemen & 4,0 & $Q t=0.6^{-0.007 t}+0.9^{-0.65 t}$ \\
\hline Kakap & 7,0 & $Q t=0.3^{-0.06 t}+0.5(1-0923 t)+0.7(1-0.0112 t)$ \\
\hline
\end{tabular}




\begin{tabular}{|l|c|l|}
\hline $\begin{array}{c}\text { Mataair } \\
\text { dan SBT }\end{array}$ & Dk & \multicolumn{1}{c|}{ Kondisi } \\
\hline Beton & 6,6 & $\begin{array}{l}\text { Karstifikasi tingkat dewasa karena pengaruh patahan dan saluran } \\
\text { karst terbuka, dengan saluran conduit dan non-karst yang telah } \\
\text { berkembang dan menuju pada perkembangan muka airtanah } \\
\text { freatik secara wilayah }\end{array}$ \\
\hline $\begin{array}{l}\text { Petoyan } \\
\text { dan } \\
\text { Sumberse } \\
\text { men }\end{array}$ & $3,7-$ & $\begin{array}{l}\text { Perkembangan jaringan fissure yang belum seragam, mayoritasnya } \\
\text { adalah makrofissure terbuka dan minim adanya saluran karst } \\
\text { (conduit). Saat periode banjir ada kemungkinan (langka) terjadi } \\
\text { aliran turbulen dalam jangka pendek }\end{array}$ \\
\hline $\begin{array}{l}\text { Gilap } \\
4,0\end{array}$ & 5,8 & $\begin{array}{l}\text { Mulai adanya karstifikasi dan pelarutan batuan karbonat, dengan } \\
\text { pelorongan yang terbentuk mulai bersifat terbuka, berukuran } \\
\text { sedang (fissure), baik dialami oleh batuan yang mudah atau sulit } \\
\text { larut di zone freatik. Sifat aliran sedikit dipengaruhi oleh saluran } \\
\text { terbuka (conduit) yang saling berhubungan }\end{array}$ \\
\hline Ngreneng & 6,0 & $\begin{array}{l}\text { Mulai adanya karstifikasi dan pelarutan batuan karbonat, dengan } \\
\text { pelorongan yang terbentuk mulai bersifat terbuka, berukuran } \\
\text { sedang (fissure), baik dialami oleh batuan yang mudah atau sulit } \\
\text { larut di zone freatik. Sifat aliran sedikit dipengaruhi oleh saluran } \\
\text { terbuka (conduit) yang saling berhubungan }\end{array}$ \\
\hline
\end{tabular}




\begin{tabular}{|l|c|l|}
\hline $\begin{array}{c}\text { Mataair } \\
\text { dan SBT }\end{array}$ & Dk & \multicolumn{1}{c|}{ Kondisi } \\
\hline Seropan & 5,2 & $\begin{array}{l}\text { Akuifer dengan adanya masukan air dari zona sesar di daerah hulu } \\
\text { (missal), dengan perkembangan jaringan saluran kecil (diffuse- } \\
\text { fissure) yang cukup intensif, sebagiannya bersifat terbuka dan } \\
\text { sudah mempunyai sistem air freatik yang bersifat terbuka }\end{array}$ \\
\hline Toto & 5,0 & $\begin{array}{l}\text { Akuifer dengan adanya masukan air dari zona sesar di daerah hulu } \\
\text { (misal), dengan perkembangan jaringan saluran kecil (diffuse- } \\
\text { fissure) yang cukup intensif, sebagiannya bersifat terbuka dan } \\
\text { sudah mempunyai sistem air freatik yang bersifat terbuka }\end{array}$ \\
\hline Bribin & 7,7 & $\begin{array}{l}\text { Karstifikasi pada tingkat yang sangat berkembang, yang didominasi } \\
\text { oleh saluran terbuka (conduit) yang besar. Peran dari saluran } \\
\text { mengengah (fissure) dan jaringan saluran kecil (diffuse network) } \\
\text { sudah sangat minim. Zona freatik sudah hilang atau perannya } \\
\text { sudah tidak lagi signifikan. Hampir seluruh siklus airtanah telah } \\
\text { bergabung pada sistem saluran terbuka. }\end{array}$ \\
\hline Ngerong & 4,8 & $\begin{array}{l}\text { Akuifer dengan adanya masukan air dari zona sesar di daerah hulu } \\
\text { (misal), dengan perkembangan jaringan saluran kecil (diffuse- } \\
\text { fissure) yang cukup intensif, sebagiannya bersifat terbuka dan } \\
\text { sudah mempunyai sistem air freatik yang bersifat terbuka }\end{array}$ \\
\hline
\end{tabular}




\section{Variasi Spasial Derajat Karstifikasi (Dk)}

Kawasan Karst bagian Timur

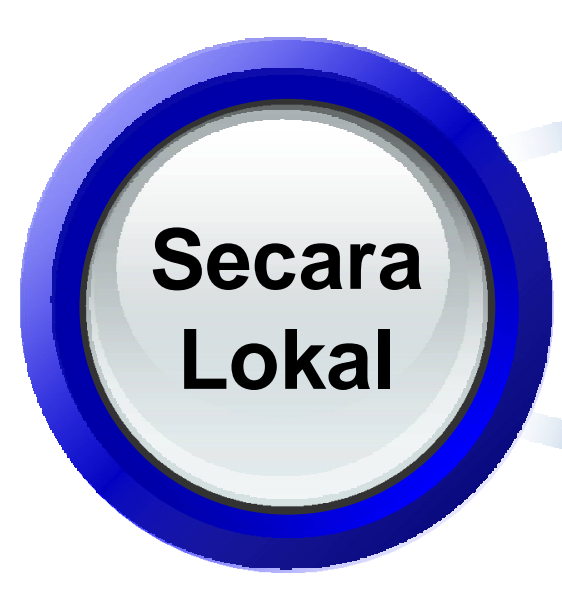

$D k=5,2-7,7$ (dewasa hingga dewasa - tua)

Kawasan Karst bagian Barat

$D k=3,7$ (muda)

Kawasan Karst Rengel, Tuban

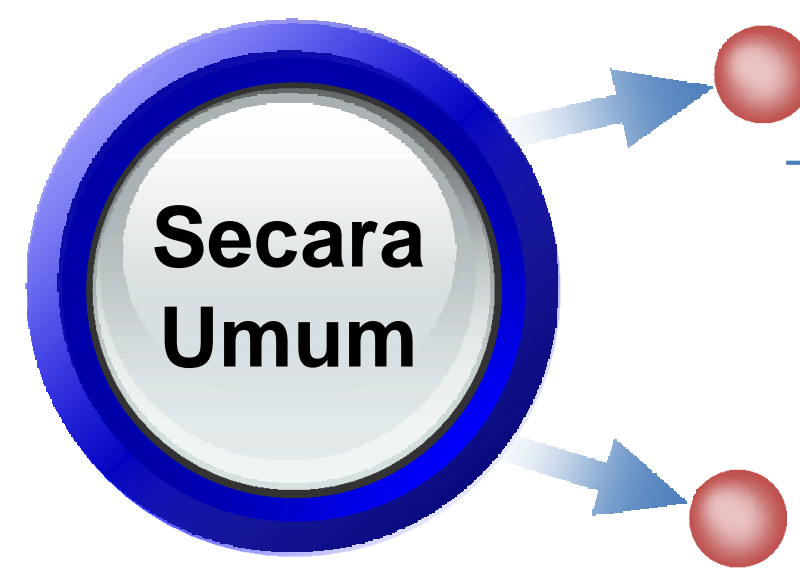

$D k=4,8$ (muda berkembang ke dewasa)

Kawasan Karst Rembang

$D k=4,0$ (muda)

Kawasan Karst Gunung Sewu

$D k=3,7-7,7$ (muda hingga dewasa - tua) 
1. Identifikasi sifat dan jenis aliran yang dominan;

2. Untuk membantu menilai tingkat kerentanan terhadap pencemaran di daerah karst

3. Menjadi penengah ketika terjadi konflik pemanfatan batugamping (misal: tambang semen) 